\title{
Accuracy of mammography and ultrasound for detecting breast cancer at a breast care clinic in Karachi, Pakistan
}

\author{
Nosheen Fatima', Maseeh uz Zaman ${ }^{2}$, Qadeer uddin ${ }^{1}$, Zehra Ahsan ${ }^{1}$ \\ 1. Karachi Institute of Radiotherapy and Nuclear Medicine (KIRAN), Karachi, Pakistan. 2. The Aga Khan University Hospital \\ (AKUH), Karachi, Pakistan.
}

Correspondence: Maseeh uz Zaman. Address: The Aga Khan University Hospital (AKUH), Karachi, Pakistan. Email: maseeh.uzzaman@aku.edu

Received: September 28, 2011

Accepted: November 10, 2011

Published: December 1, 2011

DOI : $10.5430 / j b g c . v 1 n 1 p 44$

URL: http://dx.doi.org/10.5430/jbgc.v1n1p44

\section{Abstract}

Objective: Mammography is an important screening tool which can effectively detect breast cancer earlier before it becomes palpable on breast self-examination. The main objective of this study was to determine screening accuracy of mammography and ultrasound (US) in a local population.

Methods: This prospective analysis included 1104 women (median age 40; 11-81 years) attended a breast care clinic at KIRAN for screening (559) or presented with palpable breast lump (545). As per American Cancer Society (ACS) guidelines 2003, mammogram and U.S. was performed. Fine needle aspiration cytology (FNAC) was subjected in 217 women with Breast Imaging Reporting and Data System (BIRADS) IV/V, high risk patients with III on mammography and with suspicious US findings, while women with normal to benign looking US, BIRADS I, II and III were followed after $12 \pm 3$ months.

Results: Mammography was performed on 564 (51\%) women and classified as BIRADS I in 227 (40\%), II in 110 (20\%), III in 53 (9\%), IV in $130(23 \%)$ and as V in $44(8 \%)$. Remaining 540 (49\%) women were subjected for breast US, among them 408 (76\%) were absolutely normal, 97 (18\%) revealed benign pathology and $35(6 \%)$ had suspicious findings. On FNAC, 206/217 (19\%; incidence rate $=1: 6$ with $95 \%$ CI of $1: 6$ to $1: 5, p<0.001)$ were diagnosed as breast cancer. Sensitivity, Specificity, Positive predictive value (PPV) and Negative Predictive Value (NPV) were 80.47\%, 73.07\%, $64.79 \%$ and $85.86 \%$ for mammogram; $86.84 \%, 99.6 \%, 94.29 \%$ and $99.01 \%$ for US respectively. The sensitivity, specificity, PPV and NPV of US as compared to mammogram was significantly higher, i-e. $p=0.005\left(\chi^{2}=7.701\right), p<0.0001$ $\left(\chi^{2}=159.58\right), p<0.0001\left(\chi^{2}=144.05\right)$ and $p<0.0001\left(\chi^{2}=65.22\right)$ respectively.

Conclusion: We concluded that US should be considered as a primary screening tool in younger population and as an adjunct to mammogram in elder women to minimize the chances of missing diagnosis of breast cancers.

\section{Key words}

Breast cancer, Ultrasound, Mammogram, Negative predictive value, Positive predictive value 


\section{Introduction}

Breast cancer is the most frequently diagnosed cancer among Pakistani females and reported incidence is 17\% over 2006 to 2009 and $34.6 \%$ by Karachi cancer registry [1,2]. A multi-center analysis revealed the fact that the majority of cases are presented in stage III and IV in Pakistan which warrants the need of aggressive screening program for early detection of disease [3]. Mammography is considered standard modality for screening of breast cancer and has been shown to reduce mortality as well $[4,5,6]$. In Pakistan, awareness about breast cancer screening can be assessed from the fact that only $14 \%$ of the mammography tests were performed for screening purpose in the country's leading cancer institute [7]. Despite enactment of mammography quality standards act 2001 for better image quality; wide variability in the reported accuracy of mammography and biopsy persists $[8,9]$. The screening strength of mammography is based on reported high negative predictive values (NPV) ranging from $99.8 \%-100 \%$ but wide range of PPV from $4.3 \%$ to $52.4 \%$ and false positive rates from $1.5 \%$ to $24.1 \%[10,11,12]$ resulting in un-necessary biopsies. Due to rising incidence of breast cancer in younger population; usefulness of mammography as a screening tool is undermined [13]. So it is logical to consider breast self-examination (BSE), clinical examination and ultrasound as a first choice in screening of younger population. Ultrasound has an established role in the early diagnosis of breast cancer especially in younger females ( $<35$ years of age) and also as a complimentary technique to mammogram in older females [14]. However, it is dependence upon operator's expertise is a major limitation and there is little evidence to support the use of breast ultrasound as primary modality for breast cancer screening. Screening techniques must have higher sensitivity for both palpable and non-palpable lumps, high specificity, cost effective, safe, acceptable and assessable to population being screened. Aim of this study was to find out the accuracy of mammogram and ultrasound as a screening tool for breast cancer in Pakistani women.

\section{Material and methods}

This prospective analysis recruited all women who attended breast care clinic for the first time at Karachi Institute of Radiotherapy and Nuclear Medicine (KIRAN), Karachi, Pakistan from March 2006 till February 2010. The study was duly approved by hospital ethical committee. Total 1104 women attended for screening or presented with history of palpable breast lump. Patient who had recently been diagnosed and treated for another type of cancer were excluded from this study. As per American Cancer Society (ACS) guidelines 2003 [15], mammogram and ultrasound breast were performed in studied population. All women more than 40 years or selected cases of less than 40 years (suspicious lump or strong family history) were subjected for mammogram on Metaltronica ${ }^{\circledR}$ (screen film mammogram) by taking cranio-caudal (CC) and medio-lateral oblique (MLO) views of each breast; results were categorized by Breast Imaging Reporting and Data System (BIRADS) by an expert radiologist (not by two or more radiologist which is a limitation of our study). Ultrasound was performed on Nemio 20 Toshiba ${ }^{\circledR}$ with $7.5 \mathrm{MHz}$ probe in all women less than 40 years and selected women ( $>40$ years) as complementary to mammogram where mammography findings either equivocal or inconclusive like soft tissue opacity, dense breast or lactating women. FNAC was performed in all BIRADS IV-V and in selected high risk patients with BIRADS III on mammography along with suspicious findings on ultrasound. Patients with BIRADS I, II, most of III on mammography but with normal/benign ultrasounds findings were followed $12 \pm 3$ months with either mammogram/ultrasound.

\section{Statistical analysis}

Data was analyzed by using the MedCalc statistical software version 11.3.10 and SPSS software version 10. For univariate analysis Chi square test was performed for discrete and Student's $t$-test was used for continuous variables. Receiver Operating Characteristics curves (ROC) were plotted for diagnostic strength of ultrasound and mammogram. Kaplan Meier plot for event free survival and for purpose of comparison of survival curves logrank test was applied. For all $P$-values $<0.001$ were selected as significant. 


\section{Results}

Total 1104 women with median age of 40 (age range: 11-81) years were registered at breast care clinic. Five hundred and forty-five women (49\%) presented with breast lump while remaining 559 (51\%) women attended for screening purpose having no lump with or without mastalgia (Table 1). Mammography was performed on 564 (51\%) women and they were classified as BIRADS I in 227 (40\%), BIRADS II in $110(20 \%)$, BIRADS III in 53 (9\%), BIRADS IV in 130 (23\%) and as BIRADS V in 44 (8\%). Remaining 540 (49\%) women were subjected for breast ultrasound, among them 408 (76\%) were normal, 97 (18\%) revealed benign pathology while $35(6 \%)$ had suspicious findings. FNAC was performed in 217 (20\%) women and $206(19 \%)$ were turned out to be positive for breast cancer (incidence rate $=1: 6$ with 95\% CI of 1:6 to 1:5, $p$ $<0.001$ ) (Figure 1).

Screening outcome in recruited women was demonstrated in Table 2. Sensitivity, specificity, PPV and NPV of mammogram were $80.47 \%$ (74.53\% to $85.54 \%), 73.07 \%$ (68.09\% to $77.65 \%), 64.79 \%(58.74 \%$ to $70.52 \%)$ and $85.86 \%$ $(81.37 \%$ to $89.61 \%)$ respectively; for US $86.84 \%$ (71.90\% to $95.54 \%), 99.6 \%(98.57 \%$ to $99.94 \%), 94.29 \%$ (80.81\% to $99.13 \%)$ and $99.01 \%$ (97.70\% to $99.67 \%)$ respectively. The sensitivity, specificity, PPV and NPV of US as compared to mammogram was statistically significant i-e. $p=0.005\left(\chi^{2}=7.701\right), p<0.0001\left(\chi^{2}=159.58\right), p<0.0001\left(\chi^{2}=144.05\right)$ and $p<0.0001\left(\chi^{2}=65.22\right)$ respectively.

Figure 2 demonstrated PPV of palpable lump for breast cancers on mammogram was 76\%, 100\%, 98\% and 13\% for overall, BIRADS V, IV and III respectively which was statistically significant $(p<0.001)$ for all except for BIRADS III (0.069) while PPV for ultrasound in studied population with palpable lump was $94 \%(p<0.001)$.

Receiver Operator Characteristic (ROC) analysis revealed that the diagnostic strength of US is better (0.996 area under curve) than mammogram ( 0.783 area under curve) with statistically significant p values (Figure 3 ).

NPV for breast cancer in women with previous normal or benign findings on ultrasound with BIRADS I-III mammogram on $12 \pm 3$ months follow up either by mammogram or ultrasound by Kaplan Meier survival analysis (Figure 4) was 100\% $(p<0.001)$. Comparative analysis of survival response by logrank test for normal to benign looking ultrasound and BIRADS I-III mammogram was statistically identical $(p=0.385)$.

Table 1. Demographic of study population

\begin{tabular}{lll}
\hline Variables & $\begin{array}{l}\text { Total population } \\
(\mathbf{n = 1 1 0 4 )}\end{array}$ & P value \\
\hline Age (median with range) years & $40(11-81)$ & $<0.001$ \\
Palpable lump & $545(49 \%)$ & $<0.001$ \\
No lump (Screening/Mastalgia) & $559(51 \%)$ & $<0.001$ \\
Multiparty ( $\geq 2)$ & $745(67 \%)$ & $<0.001$ \\
Breast feeding & $725(66 \%)$ & $<0.001$ \\
Family History & $57(5 \%)$ & $<0.106$ \\
Menopause & $340(31 \%)$ & $<0.001$ \\
\hline
\end{tabular}

* $\mathrm{SD}=$ Standard Deviation

Table 2. Outcome of screening by utilizing mammogram and ultrasound in studied women at their first visit at breast care clinic

\begin{tabular}{lll}
\hline & Mammogram (564) & Ultrasound (540) \\
\hline True Positive & 173 & 33 \\
True Negative & 255 & 500 \\
False Positive & 94 & 2 \\
False Negative & 42 & 5 \\
Sensitivity & $80.47 \%(74.53 \%$ to $85.54 \%)$ & $86.84 \%(71.90 \%$ to $95.54 \%)$ \\
Specificity & $73.07 \%(68.09 \%$ to $77.65 \%)$ & $99.6 \%(98.57 \%$ to $99.94 \%)$ \\
Positive Predictive Value & $64.79 \%(58.74 \%$ to $70.52 \%)$ & $94.29 \%(80.81 \%$ to $99.13 \%)$ \\
Negative Predictive Value & $85.86 \%(81.37 \%$ to $89.61 \%)$ & $99.01 \%(97.70 \%$ to $99.67 \%)$ \\
\hline
\end{tabular}




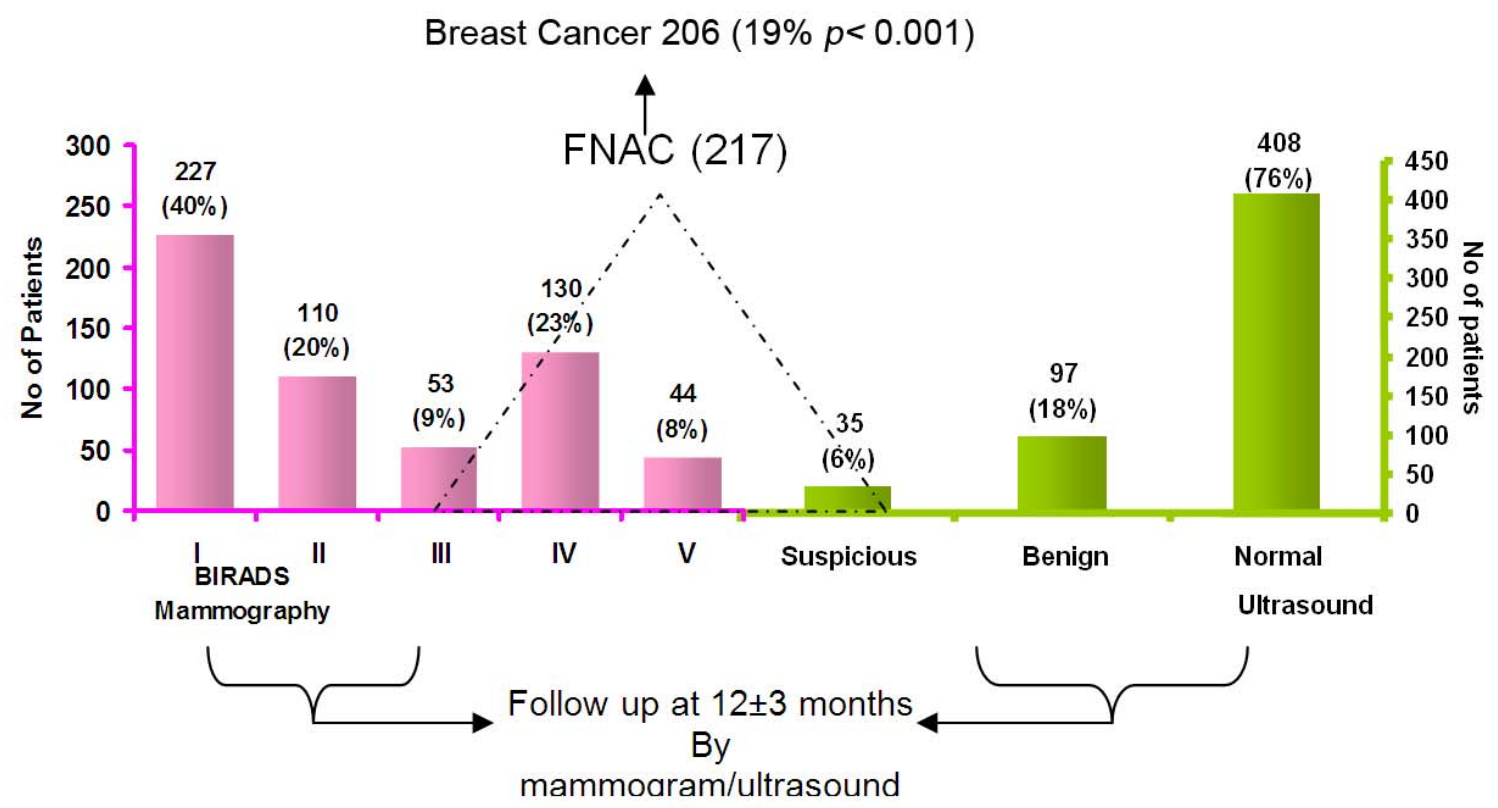

Figure 1. Schematic presentation of patient outcome *FNAC=Fine Needle Aspiration Cytology

**BIRADS $=$ Breast Imaging Reporting and Data System

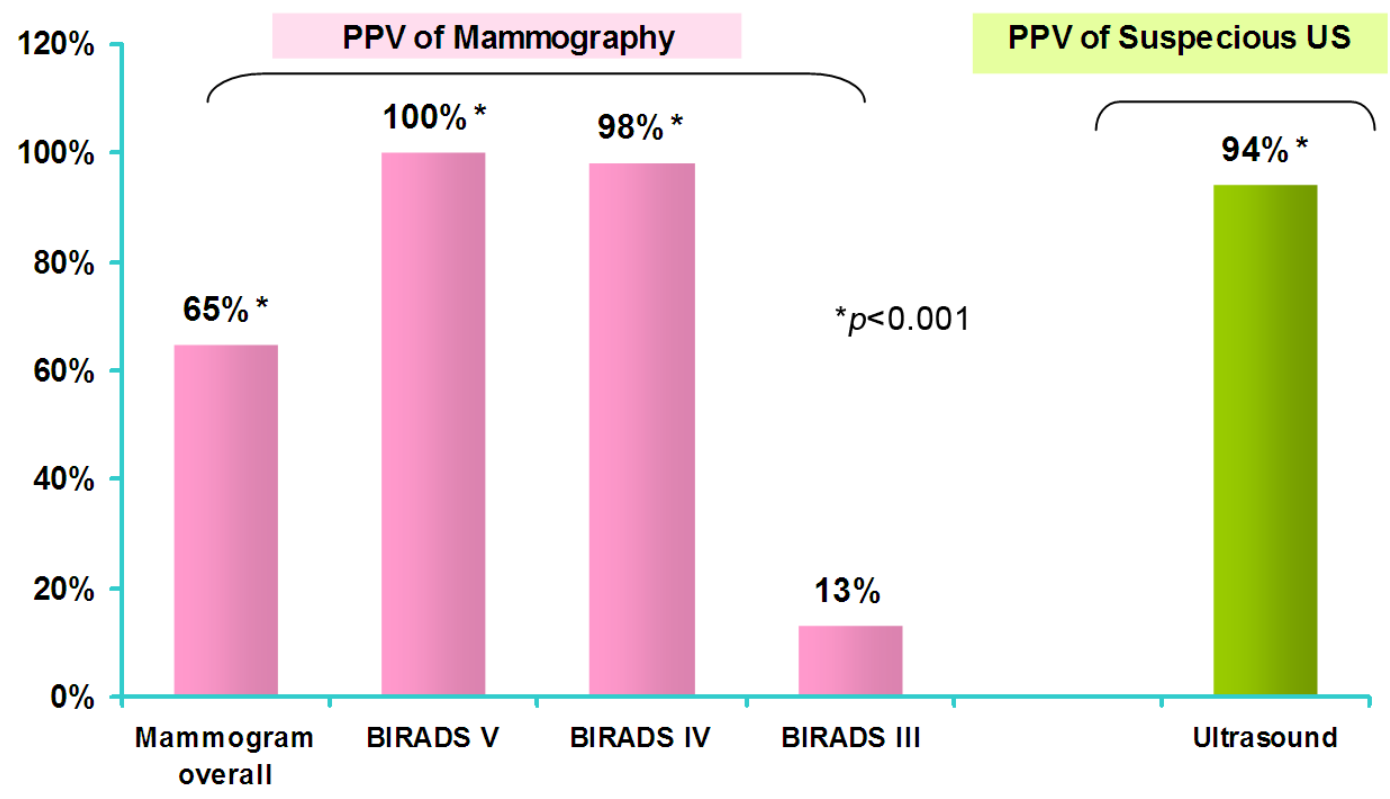

Figure 2. Positive Predictive value of mammogram and ultrasound for breast cancer 


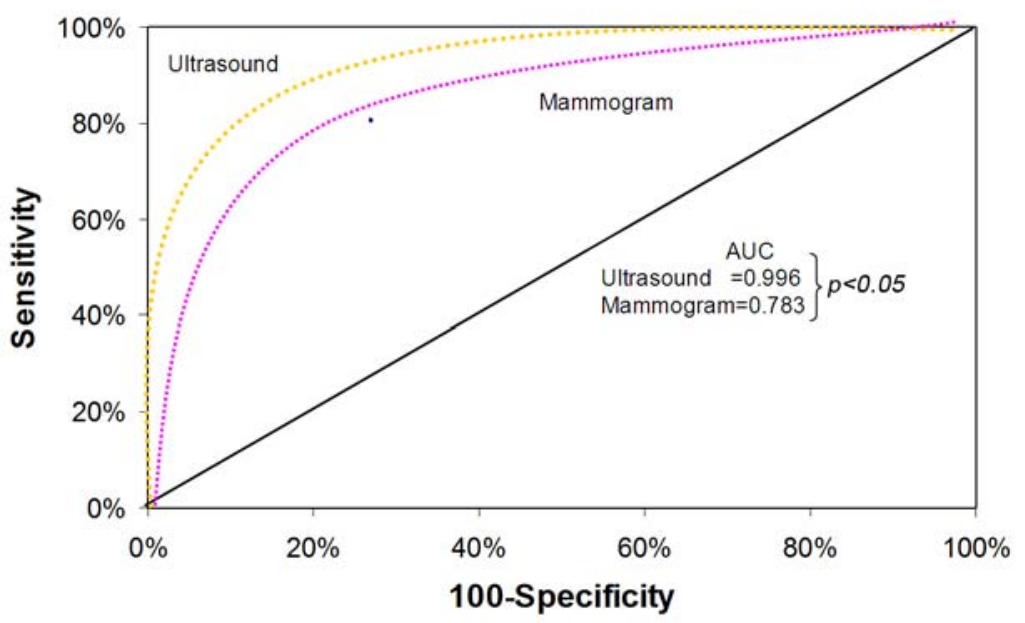

Figure 3. Receiver Operating Characteristics curve analysis of mammogram and ultrasound for breast cancer *AUC=Area Under Curve

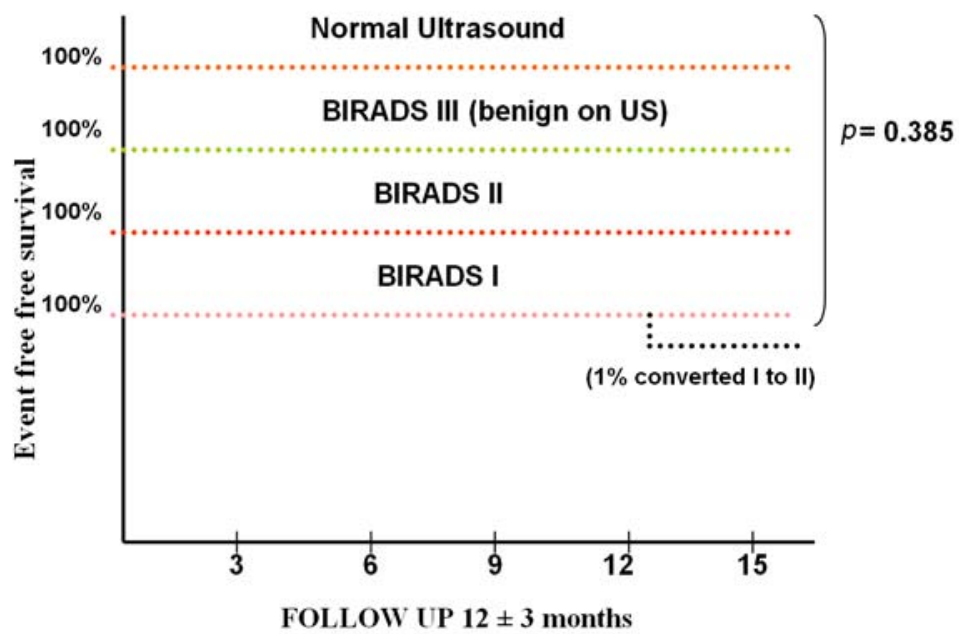

Figure 4. Kaplan Meier plot for breast cancer free survival in normal ultrasound and BIRADS I-III mammogram

\section{Discussion}

Pakistan has the highest burden of breast cancers in Asia but unfortunately no authentic national data base regarding the incidence across the country is available. The single center incidence of breast cancer published by our group was $17 \%$ which has been re-observed about $20 \%$ in the current study. The peak incidence of breast cancer in Pakistani women is 30-50 years which is considerably low as compared to western population [1,16]. This fact draws our attention towards the need of effective national breast screening program to tackle the menace of breast cancer.

The breast care clinic at KIRAN is catering about 2.5 to 3 million metropolis for the last four years and has been following the guidelines of American Cancer Society. The sensitivity and specificity of mammogram in studied population were $80.47 \%$ and 73.07 (for palpable lump and no lump cohort) respectively. As compared with study published by Kavanagh et al. 2000 upon Australian women [17], sensitivity is relatively higher ( $80.47 \%$ vs. $75.6 \%)$ but specificity was lower (73.07\% vs. 94.9\%) in asymptomatic Pakistani women. While our results were comparable with sensitivity and specificity in Australian women with lump (i.e. $80.47 \%$ vs. $80.8 \%$ and $73.07 \%$ vs. $73.7 \%$ respectively). The plausible explanation for 
this disparity is existence of only $2.6 \%$ women with palpable lumps as compared to a large number of women with lump (49\%) in our cohort. The PPV and NPV in our study are $64.79 \%$ and $85.86 \%$. The PPV in our cohort is higher $(4.3 \%$ to $52.4 \%$ ) while NPV is lower than (99.8\%-100\%) than published studies and the high prevalence of breast cancer in our population is the reason for this discordance $[10,11]$.

We used ultrasound as the primary screening imaging modality in women $<40$ years and in those women where mammogram was inconclusive like dense breast or lactating mothers. We found that the sensitivity and specificity of US in our cohort was significantly higher than mammogram which was also reiterated by ROC curve analysis that showed better diagnostic accuracy of US than mammogram. These findings are in accordance with recently published study in Bosnia and Herzegovina [18] which revealed higher diagnostic accuracy of US than mammogram in all age groups. This fact is further proven by Devolli-Disha, et al. [19] who reported that US was $20.5 \%$ more sensitive and $14.6 \%$ more specific than mammogram in symptomatic younger women $<45$ years. The higher specificity of US in our study could be explained by late arrival of symptomatic women with palpable lumps. The relatively lower sensitivity of US in asymptomatic women was probably due to suboptimal appreciation of micro calcification and chances of missing occult lesion.

Similarly PPV and NPV of US was also significantly higher than mammogram in our study i.e. $94.29 \%$ vs. $64.79 \%$ and $99.01 \%$ vs. $85.86 \%$ respectively and this might be explained by higher prevalence of breast cancer in relatively younger Pakistani women as compared to western population [16] and unfortunately no local study available for comparison of US and mammogram in this context.

We concluded that US should be considered as a primary screening tool in younger population and as an adjunct to mammogram in elder women to minimize the chances of missing diagnosis of breast cancers.

\section{References}

[1] Fatima N, Zaman M, Fatima T. Increased Risk of Breast Cancer in Multiparous and Lactating Women Attending A Breast Care Clinic in Pakistan: A Paradigm Shift? Asian Pacific J Cancer Prev. 11:1219-23. PMid: 21198266.

[2] Bhurgri Y. Karachi cancer registry data-implications for the nation al cancer control program of Pakistan. Asian Pac J Cancer Prev. 2004;5:77-82. PMid: 15075010.

[3] Gilani GM, Kamal S, Akhter AS. A Differential Study of Breast Cancer Patients in Punjab. JPMA. 2003;53:478-80. Pakistan.

[4] Kerlikowske K, Grady D, Rubin SM, Sandrock C, Ernster VL. Efficacy of screening mammography: a meta-analysis. JAMA. 1995;273:149-54. http://dx.doi.org/10.1001/jama.273.2.149

[5] Robert A. Smith, Sawyer KA, Burke W, Costanza ME, Phil Evans W, Foster RS. American Cancer Society Guidelines for Breast Cancer Screening. Update 2003. CA Cancer J Clin. 2003;54:141-69.

[6] Berry DA, Cronin KA, Plevritis SK, et al. Effect of screening and adjuvant therapy on mortality from breast cancer. N Engl J Med. 2005;353:1784-92. PMid: 16251534. http://dx.doi.org/10.1056/NEJMoa050518

[7] Badar F, Faruqui ZS, Ashraf A, Uddin N. Third world issues in breast cancer detection. J Pak Med Assoc. 2007;57:137-40. PMid: 17432019.

[8] Birdwell RL, Wilcox PA. The Mammography Quality Standards Act: benefits and burdens. Amsterdam. The Netherlands: IOS Press. 2001.

[9] Elmore JG, Miglioretti DL, Reisch LM, et al. Screening mammograms by community radiologists: variability in false-positive rates. J Natl Cancer Inst. 2002;94:1373-80. http://dx.doi.org/10.1093/jnci/94.18.1373

[10] Soo MS, Rosen EL, Baker JA, Vo TT, Boyd BA. Negative predictive value of sonography with mammography in patient with palpable breast lesions. AJR Am J Roentgenol. 2001;177:1167-70. PMid: 11641195.

[11] Rosenberg RD, Yankaskas BC, Abraham LA, et al. Performance benchmarks for screening mammography. Radiology. 2006;241:55-66. PMid: 16990671. http://dx.doi.org/10.1148/radiol.2411051504

[12] Tan A, Freeman DH Jr, Goodwin JS, Freeman JL. Variation in false-positive rates of mammography reading among 1067 radiologists: a population based assessment. Breast Cancer Res Treat. 2006;100:309-18. PMid: 16819566. http://dx.doi.org/10.1007/s10549-006-9252-6 
[13] Rizwan MM, Saadullah M. Lack of awareness about breast cancer and its screening in developing countries. Indian J Cancer. 2009;46:252-53. PMid:19574687http://dx.doi.org/10.4103/0019-509X.52969

[14] Stavros AT, Thickman D, Rapp CL, Dennis MA, Parker SH, Sisney GA. Solid breast nodules: use of sonography to distinguish between benign and malignant lesions. Radiology. 1995;196:123-24. PMid: 7784555.

[15] Smith RA, Saslow D, Sawyer KA, et al. American Cancer society guidelines for Breast cancer screening: Update. CA Cancer J Clin. 2003;53:141-69. http://dx.doi.org/10.3322/canjclin.53.3.141

[16] Bageman E, Ingvar F, Rose C. Absence of the common Insulin-like growth factor-1 19-repeat allele is associated with early age at breast cancer diagnosis in multiparous women. Br J Cancer. 2007;96:712-17. PMid: 17311016. http://dx.doi.org/10.1038/sj.bjc.6603632

[17] Kavanagh AM, Giles GG, Mitchell H, Cawson JN. The sensitivity, specificity, and positive predictive value of screening mammography and symptomatic status. J Med Screen. 2000;7:105-10. PMid:11002452http://dx.doi.org/10.1136/jms.7.2.105

[18] Mujagic S, Burina M, Mustedanagic-Mujanovic J, Sarkanovic G. The importance of combining of ultrasound and mammography in breast cancer diagnosis. Acta Medica Academica. 2011;40:27-33. http://dx.doi.org/10.5644/ama2006-124.5

[19] Devolli-Disha E, Manxhuka-Kërliu S, Ymeri H, Kutllovci A. Comparative accuracy of mammography and ultrasound in women with breast symptoms according to age and breast density. Bosn J Basic Med Sci. 2009;9:131-36. PMid: 19485945. 